\title{
FIBRE REINFORCED MORTAR APPLICATION FOR OUT-OF-PLANE STRENGTHENING OF SCHIST WALLS
}

\author{
Mattia Colombo $^{\text {a* }}$, Tiago Valente ${ }^{\mathrm{b}}$, Joaquim A.O. Barros ${ }^{\mathrm{c}}$, Alessandra Aprile ${ }^{\mathrm{d}}$, Lúcio Lourenço $^{\mathrm{e}}$
}

\begin{abstract}
The aim of the present work is to assess the effectiveness of an innovative strengthening technique for the rehabilitation of masonry buildings deficiently prepared to resist to loading conditions typical of seismic events. This technique is based on the application of outer layers of fibre reinforced mortar (FRM) by spray technology and it is used for increasing the load carrying capacity and deformation ability of masonry elements. For this purpose three almost real scale schist walls prototypes were strengthened and tested. The experimental program is described and the relevant results are presented and discussed. For estimating the properties of the schist walls and FRM taking into account the application conditions, the tested prototypes were simulated with a FEM-based computer program that has constitutive models for the simulation of the nonlinear behaviour of these materials. By using the derived properties, a parametric study was conducted to identify the influence of the FRM properties on the performance of the proposed strengthening system.
\end{abstract}

Keywords: Schist masonry, Fibre-Reinforced Mortar, Spray system, Out-of-plane testing, Numerical simulation.

\section{Introduction}

Schist constructions represent a very important reality within the cultural, historical and architectural European heritage that need to be preserved. Different construction methodologies, building typologies and adopted materials have been used in schist masonry constructions [1, 2]. For this heterogeneity it contributes the region where schist is extracted, leading to materials with different physical and mechanical characteristics, and also the economic, cultural and social characteristics of the region $[3,4]$.

Like other natural materials, schist masonry inevitably loose material performances due to ageing effects, mainly the low strength mortar used to bond the schist units, and the external micro-structure of the schist units. Therefore, in certain circumstances the overall behaviour of the building can be

\footnotetext{
${ }^{a}$ Dept. of Eng., University of Ferrara, 44121 Ferrara, Italy. E-mail: mattia.colombo@ @nife.it (*corresponding author)

b CiviTest, Parque Industrial de Jesufrei, 4770-160 JESUFREI, VNF, Portugal. E-mail: tiagovalente@civitest.com

c ISISE, Dept. of Civil Eng., Univ. of Minho, Azurém, 4810-058 Guimarães, Portugal. E-mail: barros@ civil.uminho.pt

${ }^{d}$ Dept. of Eng., University of Ferrara, 44121 Ferrara, Italy. E-mail: alessandra.aprile@ unife.it

${ }^{\text {e }}$ CiviTest, Parque Industrial de Jesufrei, 4770-160 JESUFREI, VNF, Portugal. E-mail: luciolourenco@civitest.com
} 
deficient, and its structural safety can be considerably compromised [5-7]. In addition, masonry buildings are the most vulnerable structures to earthquakes, mainly those made by schist units due to the deficient bond between the constituent materials. For this reason, the rehabilitation and strengthening of masonry walls is a demanding task, especially after the recent earthquakes that demonstrated the vulnerabilities of this type of constructions (e.g. L'Aquila, Italy in 2009; Christchurch, New Zealand in 2010; Lorca, Spain in 2011).

Furthermore, the upgrade of these constructions, promoting the living quality for their users, can contribute for attracting tourism for the interior regions of the countries, decreasing the huge depopulation of the regions occurred in the last decades.

Several kinds of materials have been used for the strengthening of masonry walls, like reinforced concrete, iron or steel, in an attempt of overcoming its brittle nature. However, these conventional retrofitting techniques demonstrate several disadvantages such as the reduction of available space, architectural impact, heavy mass addition, potential corrosion etc. [8, 9]. Recently, advanced materials, like Fiber Reinforced Polymers (FRPs), have been also explored for the retrofitting of masonry structures since they have high strength to weight ratio, are ease of applying, and are immune to corrosion [10-13]. However, FRP's have low bond performance to these types of substrate, mainly when submitted to wet-dry cycles [14].

Considering the seismic response of stone masonry walls, the deficient out-of-plane load capacity is the main reason of vulnerability observed in the post-earthquake damage surveys. Despite that, relatively few experimental research was carried out for the characterization of the out-of-plane behaviour of stone masonry walls [15-19].

This research aims to contribute for the mitigation of masonry elements vulnerability, by characterizing the out-of-plane behaviour of unreinforced schist masonry walls, and exploring the potentialities of an innovative strengthening technique to increase the out-of-plane load carrying capacity and deflection performance of this type of constructions. In particular, this research provides a practical methodology for the application of a non-conventional strengthening system, and proposes a reliable methodology for the assessment of the relevant characteristics of the applied materials. The proposed strengthening technique is based in spraying thin outer layers of Fibre Reinforced Mortar (FRM).

For the assessment of the effectiveness of this technique, an experimental program was carried out with almost real scale schist walls subjected to out-of-plane three points bending test setup. The loaddeflection relationships, the crack patterns and the failure modes of strengthened and unstrengthened prototypes were obtained and discussed.

For assessing the relevant properties of the constituents that form this complex constructive system, the tested prototypes were simulated by using the FEMIX 4.0, a computer program based on the finite 
element method (FEM) that includes constitutive models capable of simulating the nonlinear behaviour of several types of materials. By using this software, a parametric study was conducted to estimate the potentialities of this proposed strengthening technique, by investigating the influence of variables like: thickness of FRM and post-cracking performance of FRM.

\section{$2 \quad$ Experimental Program}

\subsection{Properties of the constituent materials}

The materials adopted in the present experimental research can be classified into two main categories: materials belonging to the schist masonry of the north-western regions of Portugal, namely stones and mortar, and Fibre Reinforced Mortar (FRM) with engineered properties in order to have fresh requisites for being applied with spray-up technique, and with hardened properties for being effective for the structural strengthening of this type of masonry walls.

The schist stones for building the masonry wall prototypes of the tests program had irregular size and shape and were collected from a demolished house in the Portuguese Ovar costal city. Due to their geological formation, their physical and mechanical properties, such as Young's modulus, strength and permeability, are strongly dependent of the direction they are evaluated, due to the pronounced material orthotropy, as demonstrated elsewhere [20].

To bond the schist units, a Hydraulic Lime based Mortar (HLM) was used, which was prepared by a worker specialized in the reconstruction of this type of buildings. For this purpose it was used constituents similar, as much as possible, to those used in the original schist based housing, namely a type of clay that incorporates sand, with size grains ranging from $0.01 \mathrm{~mm}$ to $10 \mathrm{~mm}$, hydraulic lime (HL5 according to the BS EN 459-1 [21]) and water. A binder/clay ratio of 1:7, and a water/binder ratio of 0.6 (all ratios in weight) were used. The HLM mechanical properties were assessed according to the EN 1015-11 [22] on three sets of three prismatic samples $\left(160 \times 40 \times 40 \mathrm{~mm}^{3}\right)$, casted on metal moulds during the schist walls construction, and then stored in a humidity chamber. To evaluate the development of the HLM strength over the time, the three aforementioned sets were tested in bending and in compression at three different ages: 28, 60 and 127 days after casting. The average flexural strength obtained for the aforementioned ages was $0.24,0.29$ and $0.33 \mathrm{~N} / \mathrm{mm}^{2}$, respectively, whereas the compressive strength was $1.1,1.2$ and $2.3 \mathrm{~N} / \mathrm{mm}^{2}$, respectively.

The FRM was made up by mixing the following constituents (in weight): cement $42.5 \mathrm{R}(25.13 \%)$, fly ash $(30.75 \%)$, fine sand $(20.1 \%)$, water $(17.93 \%)$, superplasticizer $(0.97 \%)$, viscosity controller $(0.16 \%)$, glass $(4.41 \%)$ and polypropylene fibres $(0.55 \%)$. Both types of fibres have $12 \mathrm{~mm}$ of length, while the diameter is and $0.2 \mathrm{~mm}$ and $0.7 \mathrm{~mm}$, respectively, for the glass and polypropylene fibres. By executing flow table tests according to EN 1015-3 [22], a flow value of $185 \mathrm{~mm}$ was measured in 
the developed FRM [23]. Additionally, a total air content of $6.5 \%$ was measured in the tests executed according to the recommendations EN 1015-7 [24].

The FRM strength was evaluated by executing flexural and compressive tests according to the recommendations of EN 1015-11 [25]. Three sets of three prismatic samples of FRM $\left(160 \times 40 \times 40 \mathrm{~mm}^{3}\right)$, casted on metal moulds and cured in a humidity chamber, were tested at 28,48 and 104 days. The samples exhibited an average flexural strength of $11.8(9.4 \%), 16.1$ (6\%) and 15.9 (7.9\%) N/mm² at, respectively, 28, 48 and 104 days, while the average compressive strength was 25.7 $(5.4 \%), 30.5(4.3 \%)$ and $29.9(10 \%) \mathrm{N} / \mathrm{mm}^{2}$, respectively, where the values into round brackets are the corresponding coefficient of variation.

Since the FRM was designed to be applied to the outer surfaces of schist wall prototypes by spray-up technology, the adhesion between the FRM and the schist substrate was investigated by means of pull-off tests (Fig. 1), executed according to EN 1015-12 [26] recommendations.
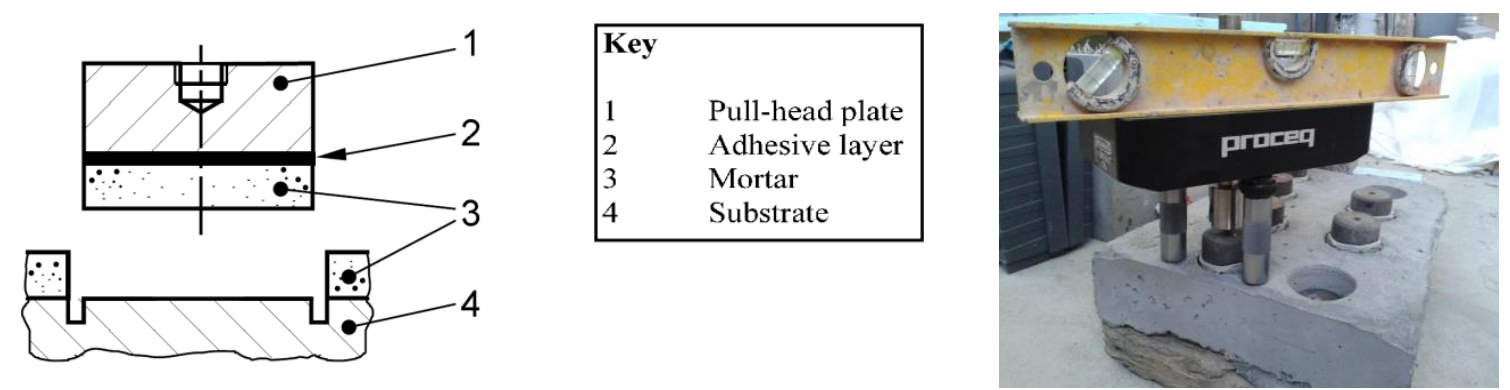

Fig. 1 - Adhesive strength investigation through Pull off test.

This test consisted in the application of a tensile load to the FRM-schist stone system by means of a standard pull-head circular steel plate $(\phi 50 \mathrm{~mm})$ glued with epoxy resin to the test area of the FRM surface. Seven pull-off test specimens were executed, and the pull-off strength was calculated as the quotient between the maximum load and the test area $\left(1963.5 \mathrm{~mm}^{2}\right)$. A predominant adhesion type fracture failure mode occurred, and the average value of adhesive strength was $0.64 \mathrm{~N} / \mathrm{mm}^{2}$, with $\mathrm{CoV}$ of $28.2 \%$, which is similar to the results obtained by other researchers for this type of substrate but using different mortars [27].

\subsection{Influence of the FRM application in its flexural behaviour}

The strengthening technique consists of spraying onto the outer surfaces of the schist masonry walls three consecutive FRM layers, of a thickness of about $10 \mathrm{~mm}$ per layer, up to its final thickness (Fig. 2a). Each layer is compacted with a roller/spatula applied in vertical direction (Fig. 2b). The walls were maintained in vertical position in order the application procedure be identical to the real strengthening conditions. 


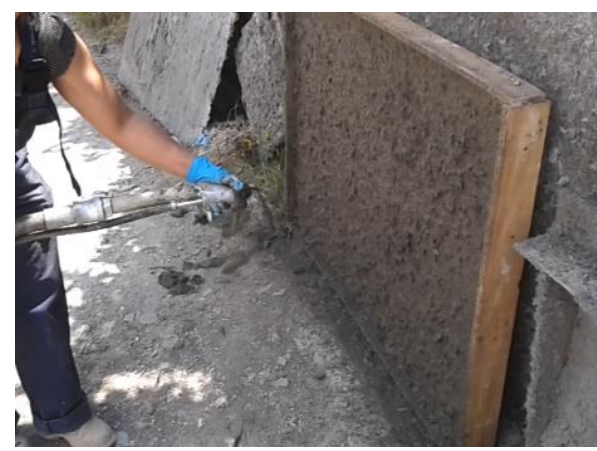

(a)

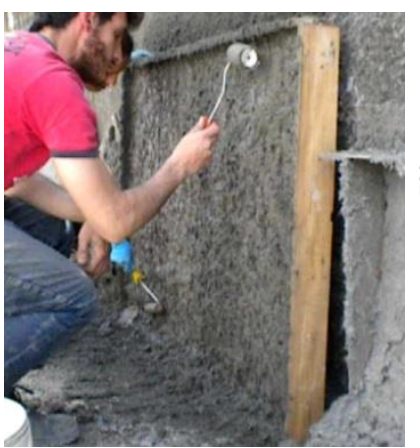

(b)

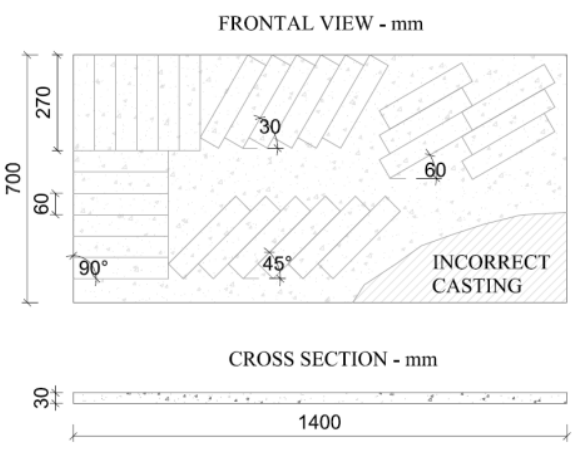

(c)

Fig. 2 - Strengthening technique: (a) Spraying operation; (b) Surface treatment with the roller; (c) Samples layout.

Once the spraying pressure, FRM rheology and distance between the operator and the sprayed surface were established, a FRM panel (see Fig. 2a and Fig. 2b) of 30mm thickness was prepared by using the same application procedure subsequently adopted for the schist masonry walls. For this purpose, a plywood panel with dimensions of 30x700x1400 $\mathrm{mm}^{3}$ was used as support for the FRM layer. This panel, throughout its curing time, was maintained rigorously in vertical position and stored in natural environmental conditions (temperature varying between $10.0^{\circ} \mathrm{C}$ and $20.0^{\circ} \mathrm{C}$; and humidity ranging between $65 \%$ and $75 \%$ ). Afterwards, samples with a cross section of about $60 \times 30 \mathrm{~mm}^{2}$ and length of $270 \mathrm{~mm}$ were obtained by cutting the FRM panel according to the layout indicated in Fig. 2c in order to assess the influence of the orientation of failure crack in the flexural behaviour of the FRM. For this purpose the following orientations were considered: $0^{\circ}, 30^{\circ}, 45^{\circ}, 60^{\circ}, 90^{\circ}$. These samples were tested at 28 days after casting, under 4-point bending loading configuration, following the ASTM C 1609 [28] recommendations. The flexural stress was determined from the following equation:

$$
\sigma_{f l}=1.5 F \cdot l /\left(b . h^{2}\right)
$$

where $b=60 \mathrm{~mm}$ and $h=30 \mathrm{~mm}$ are the width and height of the specimens cross section.

To assess the influence of spray-up conditions into vertical surfaces on the flexural behaviour of FRM, a FRM panel of 600x600 $\mathrm{mm}^{2}$ was also cast, but following gravity pouring conditions into a mould placed in a horizontal pavement. Specimens were also cut from this panel following the layout represented in Fig. 2c. These samples were also tested in 4-point bending at 28 days. The flexural deflection was measured by means of a LVDT, positioned in the mid-span of each specimen. The average curves for each orientation considered in spray-up and horizontal casting are represented in Fig. 3. 


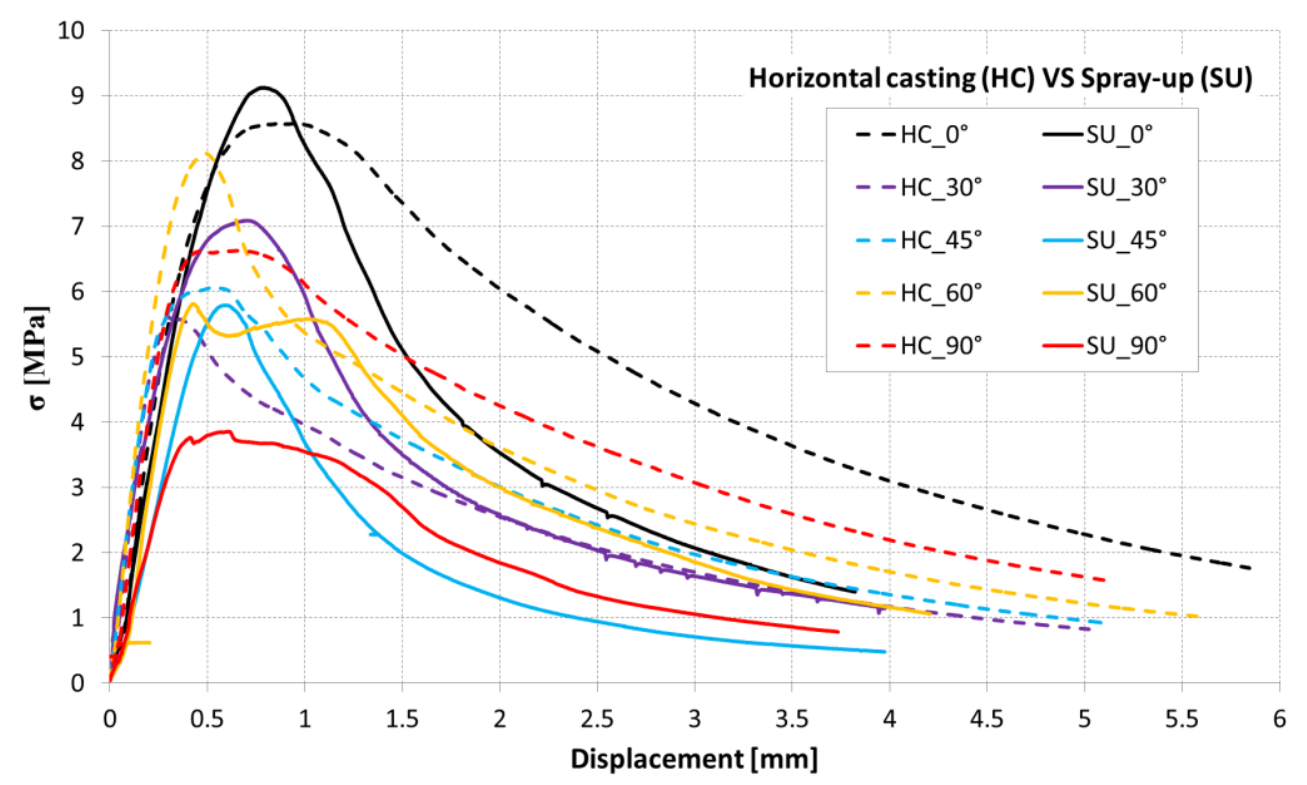

Fig. 3 -Flexural stress vs Central deflection in specimens extracted from a FRM panel produced by: spray-up

(SU) against a vertical mould (continuous line); pouring in gravity direction (HC) into a horizontal mould (dashed line).

From Fig. 3 it is possible to highlight that FRM exhibits an anisotropic behaviour, attaining higher flexural strength for the specimens extracted with a $0^{\circ}$ orientation, which is the preferential orientation applied with the roller. Despite the peak values are very similar, the FRM specimens extracted from the horizontally casted panel showed a more ductile behaviour with a softer slope in the post-peak stage. This is mainly due to the formation of more voids during the vertical casting compared to the horizontal one. In fact, the presence of more voids in the matrix has a detrimental effect on the frictional stage of the fibre reinforcement mechanism [29]. More details in this respect can be also found elsewhere [30].

\subsection{Schist masonry prototype}

Three almost full-scale schist masonry prototypes of 300x350x2000 $\mathrm{mm}^{3}$ were built using the materials presented in section 2.1. Two of them, denominated FRM_1 and FRM_2, were strengthened with two outer layers of FRM, of about $25 \mathrm{~mm}$ of thickness, and the third one, named REF, was assumed as the reference prototype, without any type of strengthening.

As shown in Fig. 4, the prototypes were built within timber moulds in order to allow a straight construction and to prevent the occurrence of damages during the walls transportation, and installation in the testing frame. The erection of each schist masonry core followed a phased construction, by means of half-meter sections at a time, interrupting the construction until the HLM has been hardened, according to the local building techniques. Schist stones were arranged, positioning them firstly in the corners and then in the central part of the prototype section, and they were covered with HLM joints of approximately $15 \mathrm{~mm}$ thickness. After 28 days, two prototypes 
were strengthened by using the spray-up technique (see Fig. 4a and Fig. 4b), achieving a final cross section area of $350 \times 350 \mathrm{~mm}^{2}$.

In the bottom of each prototypes, two steel plates (dimensions $15 \times 350 \times 350 \mathrm{~mm}^{3}$ ), with two sheets of Teflon with oil between them, were introduced in order to minimize the friction due to the self-weight of the prototypes (see Fig. 4c).

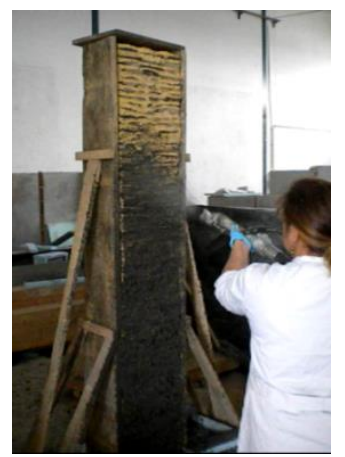

(a)

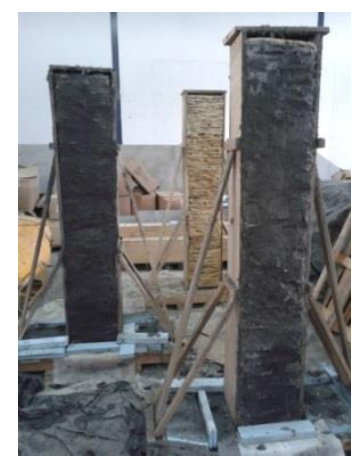

(b)

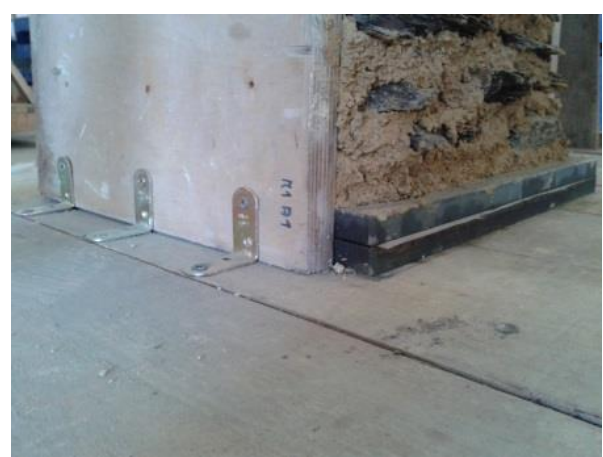

(c)

Fig. 4 - Strengthening of the schist masonry prototypes: (a) Spray operation; (b) Appearance after strengthening layout; (c) Detail of the bottom zone.

\subsection{Test setup and procedure}

To assess the strengthening system effectiveness towards out-of-plane loads, the schist walls prototypes were tested under 3-point bending configuration. Due to the size of the prototypes and their brittleness, mainly the unstrengthened one, the tests were performed with the prototypes arranged vertically. For this purpose, a reaction frame with an actuator positioned horizontally was assembled (Fig. 5), and steel cylinders (in between the I-shaped steel profiles and the prototype's surface) positioned with grout bedding courses were used for the line supports and line load. The grout had the purpose of regularize the contact conditions between the steel cylinders and the corresponding prototype's surface. Line supports were placed at $150 \mathrm{~mm}$ from the prototype extremities (top and bottom), leading a distance of $1700 \mathrm{~mm}$ between supports, whereas the line load was applied in the mid-span of the prototype by using a servo actuator of $500 \mathrm{kN}$ capacity and 200 $\mathrm{mm}$ of stroke, equipped with a load cell of $500 \mathrm{kN}$ capacity and $0.05 \%$ of accuracy.

Ten LVDTs were positioned according to the arrangement shown in Fig. 5a. Those of larger measuring length were positioned in the central part of the prototypes, while the LVDTs of smaller stroke were placed closer to the prototypes extremities. The LVDTs were installed in magnetic bases fixed to an external frame in order to minimize the registration of parasitic displacements by the LVDTs.

All prototypes were submitted to a monotonic loading under displacement control at a constant rate of $0.01 \mathrm{~mm} / \mathrm{s}$. 


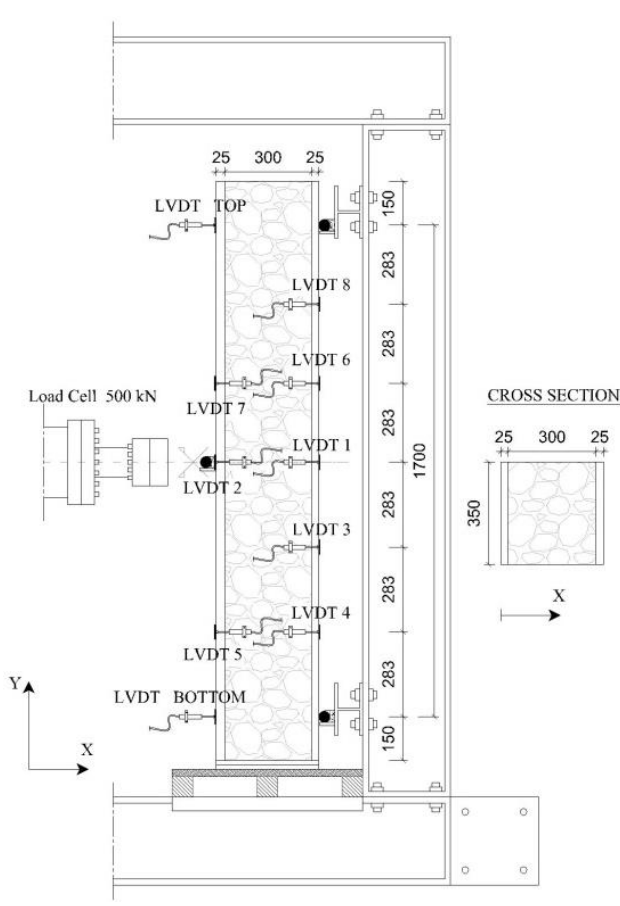

(a)

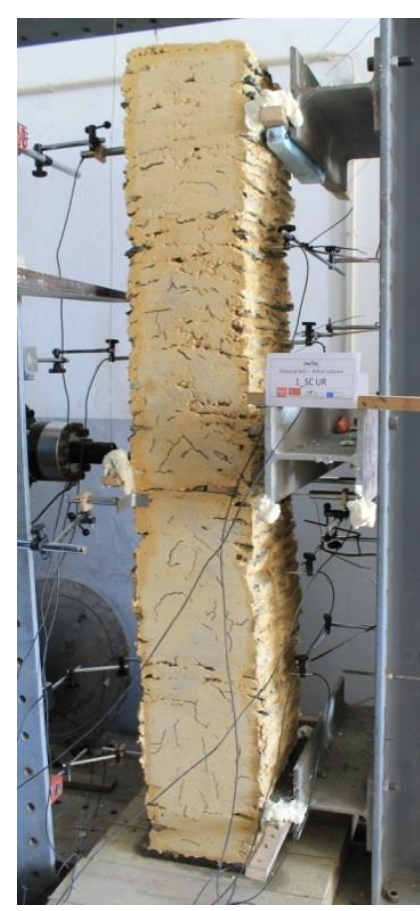

(b)

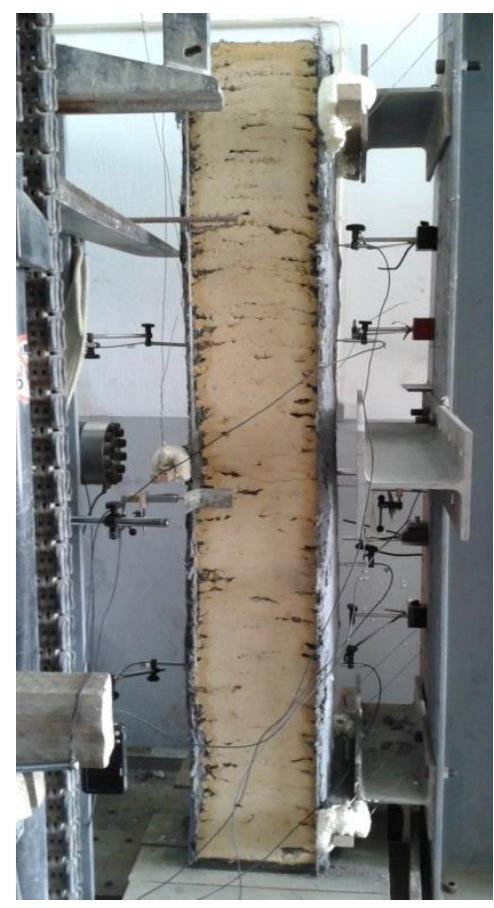

(c)

Fig. 5 - Test setup and instrumentation: (a) Schematic representation (dimensions in mm); (b) Unreinforced prototype; (c) Strengthened prototype.

\section{Results}

\subsection{Unstrengthened prototype}

The load versus displacement recorded in the installed LVDTs are depicted in Fig. 6. The response has a nonlinear character up to the peak load due to the high heterogeneity of this construction system, and low bond strength between schist unities and surrounding HLM. The peak load of $2.15 \mathrm{kN}$ occurred for a mid-span deflection of $1.81 \mathrm{~mm}$. After peak load, this reference prototype entered in a structural softening stage with a smooth load decay.
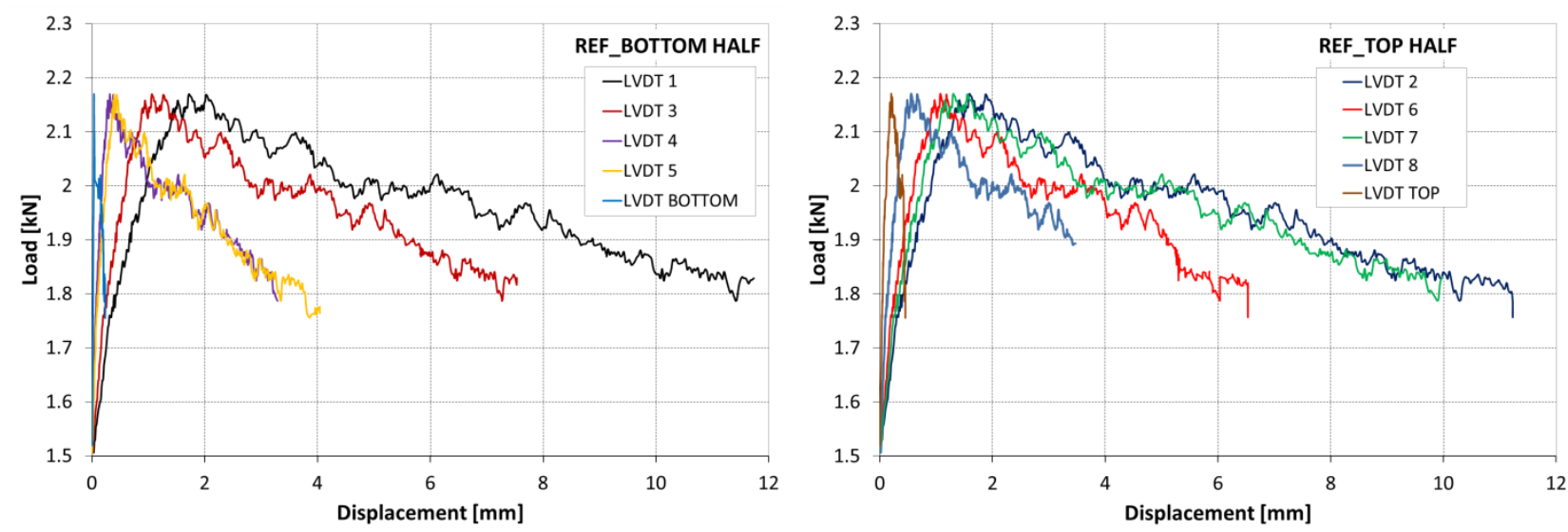

Fig. 6 - Load vs displacement responses of REF prototype. 
The largest displacements were recorded by centrally positioned LVDTs, as expected, while the displacements became smaller gradually moving away from the prototype mid-span. The LVDTs positioned at the support lines recorded negligible settlements, proving the support system effectiveness. Furthermore, it was verified that the prototype exhibited a non-symmetrical response, since LVDT 4 had smaller displacements than the corresponding LVDT 8 symmetrically positioned. In terms of load carrying capacity, the unreinforced prototype reached a maximum load of $2.15 \mathrm{kN}$, exhibiting a small inelastic deflection before peak load, in consequence of its brittle nature. A smooth slope and relatively high load fluctuations have characterized the post peak branch. These effects were due to the opening of several internal fractures as a consequence of the de-bonding between schist units and mortar joints.

Analysing the crack pattern at the peak load (see Fig. 11b), a main crack was identified in the midspan of the prototype that opened gradually until the end of the test, reaching a final width of approximately $10 \mathrm{~mm}$. After the peak, an additional crack occurred aligned to the bottom support line (see Fig. 11d). The appearance of this last crack was caused by the restriction imposed to the rotation of the specimen's surface in contact with the supporting platform. This is due to the prototype weight and to the friction developing at the supporting platform. Effectively, the adopted supporting apparatus did not completely prevent the development of friction restrain, and therefore the prototype weight contributed to the restriction of the bottom sample deformation, which created a partially fixed support conditions instead of a free edge.

It was observed that all cracks in the reference prototype occurred in the schist units-mortar interfaces, demonstrating the existence of a very small bond strength between schist units and the HLM joints.

\subsection{Strengthened prototypes}

The load - displacement responses for the two strengthened prototypes are reported in Fig. 7.

In terms of displacements, some similarities can be found comparing the strengthened and unstrengthened prototypes: the higher displacements occurred in the mid-span of the prototype, whereas lower displacements were recorded at the prototype extremities, therefore local failure modes did not occur up to peak load capable of changing significantly the expected four point loading response of the tested prototypes; the deformational behaviour was not symmetrical since the prototype top part had higher deformability than the bottom part; the settlements in the line supports were very small, proving the support system was effective. 

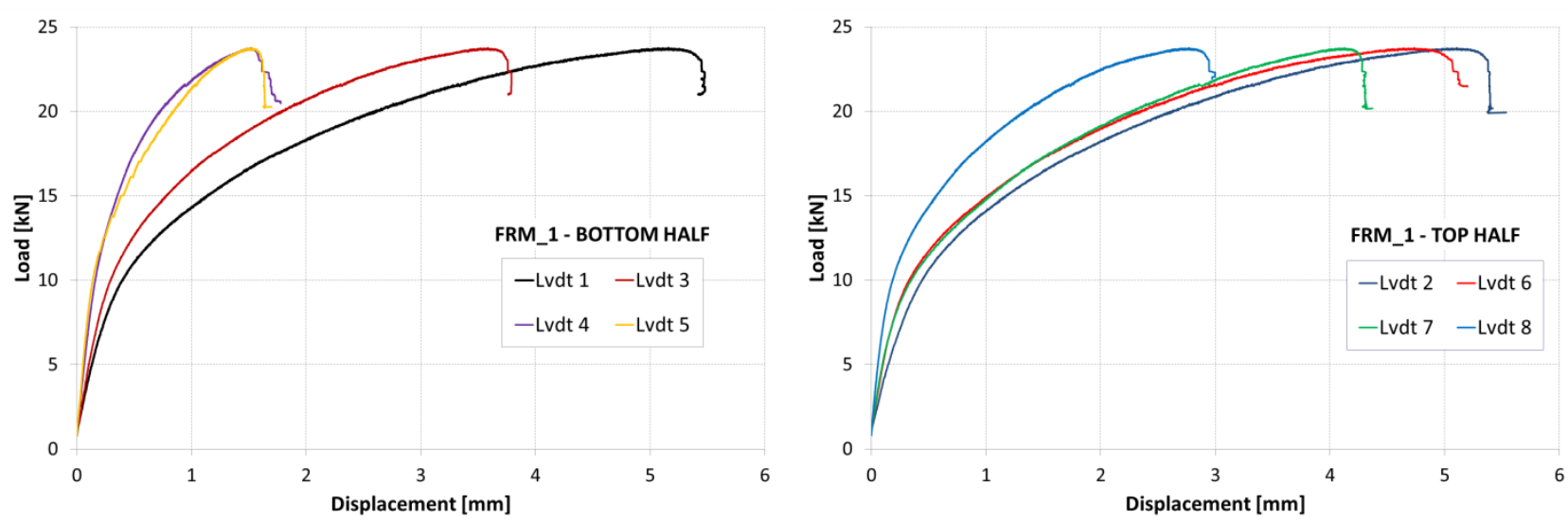

(a)
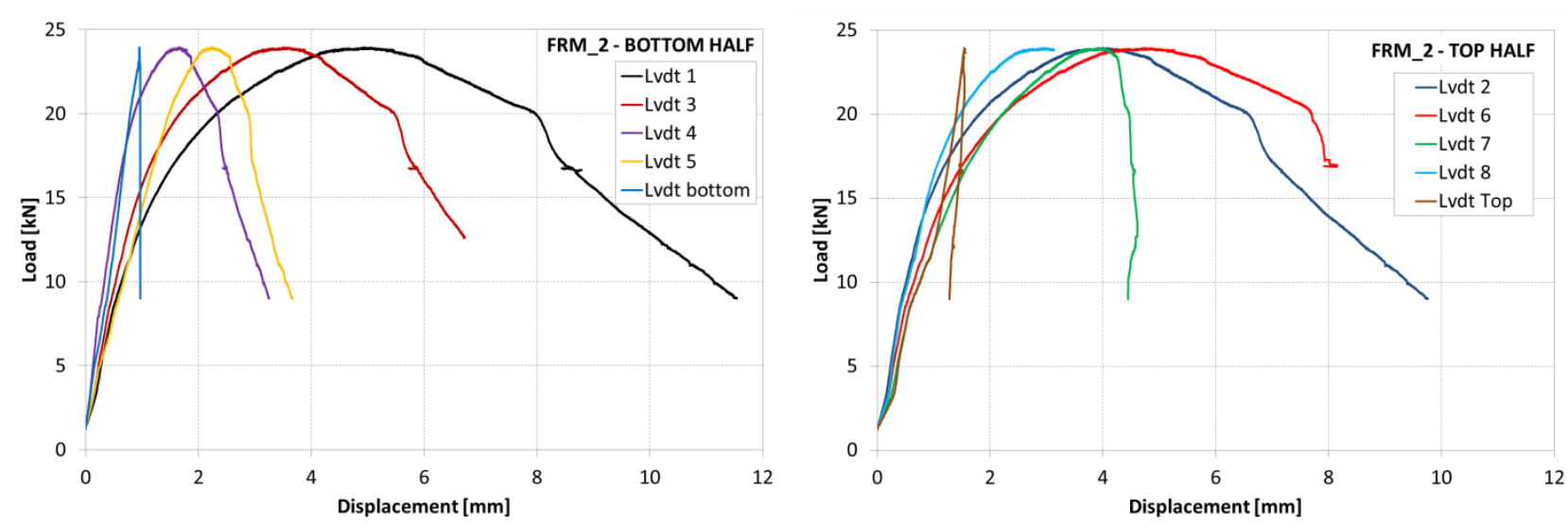

(b)

Fig. 7 - Load vs displacement relationship of: (a) FRM_1; (b) FRM_2.

Both strengthened prototypes exhibited a similar behaviour until the peak load was reached. In particular, a nearly elastic behaviour developed up to $10 \mathrm{kN}$, followed by a long inelastic branch until the peak that occurred around $24 \mathrm{kN}$ in both cases. Regarding the post peak branch, some differences appeared between the two strengthened prototypes, probably due to their heterogeneities. The FRM_2 prototype presented a more ductile post-peak response compared to the FRM_1.

Analysing the crack patterns at the peak load, both specimens exhibited shear cracks in the upper half part (see Fig. 14b), with an average inclination of $30^{\circ}$ respect to the vertical direction, connecting the load application point to the upper support. Additionally, similar cracks occurred in the bottom half part of the FRM_1 prototype, but with smaller size. At the peak load, no cracks were identified in the FRM strengthening layers. During the loading process, the cracks that appeared in the upper part of the inner core (schist units bonded with HLM joints) have increased their size and number, whereas those occurred in the bottom part did not show remarkable variations.

At near-collapse conditions, the prototypes exhibited a single macro-crack in the top part of the FRM layer intrados (see Fig. 14e).

Two main reasons contributed to the occurrence of the aforementioned crack patterns: 
1) Due to the support conditions of the bottom part of the prototype, a smaller number of cracks was formed in the prototype lower part when compared to the upper part. This would have been caused by the restrictions to the free rotation provided by these support conditions, combined with the axial load due to the prototype's self-weight that introduced a confinement effect and decreased the maximum tensile stress in this zone.

2) Due to gravity effect while spraying up the FRM layers, a tendency for the increase of the FRM layer's thickness from top to bottom of the prototype is expected. In spite of being a relatively small difference, it might be sufficient to contribute for the different crack pattern in the top and bottom halves of the prototype.

\subsection{Comparison of results}

The assessment of the strengthening technique effectiveness was carried out comparing the behaviour of the prototypes in terms of load and deformation capacity.

Regarding the load carrying capacity, the strengthened prototypes exhibited an extraordinary increase, reaching a peak load of approximately 10 times higher than the reference prototype. In fact, the REF prototype supported a maximum load of $2.15 \mathrm{kN}$, whereas prototypes FRM_1 and FRM_2 were capable of supporting a maximum load of $23.8 \mathrm{kN}$ and $23.9 \mathrm{kN}$, respectively.

Regarding the deformation capacity, the strengthened prototypes demonstrated a meaningful increase of about $340 \%$ when compared to the reference prototype. The deflections at peak load of the tested prototypes and their relative increase when compared to the ones of the reference prototype are summarized in Table 1.

Table 1 - Displacements at the peak load and relative increments.

\begin{tabular}{lcccccc}
\hline & REF & FRM_1 & FRM_2 & $\begin{array}{c}\text { FRM_1 vs } \\
\text { REF } \\
{[\%]}\end{array}$ & $\begin{array}{c}\text { FRM_2 vs } \\
\text { REF } \\
{[\%]}\end{array}$ & $\begin{array}{c}\text { Average } \\
{[\%]}\end{array}$ \\
\hline Lvdt 1 & 1.81 & 5.16 & 4.92 & $285.1 \%$ & $271.8 \%$ & $278.5 \%$ \\
Lvdt 2 & 1.68 & 5.11 & 3.99 & $304.2 \%$ & $237.5 \%$ & $270.8 \%$ \\
Lvdt 3 & 1.12 & 3.58 & 3.50 & $319.6 \%$ & $312.5 \%$ & $316.1 \%$ \\
Lvdt 4 & 0.33 & 1.52 & 1.65 & $460.6 \%$ & $500.0 \%$ & $480.3 \%$ \\
Lvdt 5 & 0.41 & 1.53 & 2.23 & $373.2 \%$ & $543.9 \%$ & $458.5 \%$ \\
Lvdt 6 & 1.12 & 4.74 & 4.72 & $423.2 \%$ & $421.4 \%$ & $422.3 \%$ \\
Lvdt 7 & 1.38 & 4.13 & 3.91 & $299.3 \%$ & $283.3 \%$ & $291.3 \%$ \\
Lvdt 8 & 0.59 & 2.77 & 2.92 & $469.5 \%$ & $494.9 \%$ & $482.2 \%$ \\
Lvdt Top & 0.21 & $\mathrm{NA}^{(*)}$ & 1.54 & $\mathrm{NA}^{(*)}$ & $\mathrm{NC}^{(* *)}$ & $\mathrm{NA}^{(*)}$ \\
Lvdt Bottom & 0.04 & $\mathrm{NA}^{(*)}$ & 0.95 & $\mathrm{NA}^{(*)}$ & $\mathrm{NC}^{(* *)}$ & $\mathrm{NA}^{(*)}$ \\
\hline
\end{tabular}

(*) NA - Not Available.

(**) NC - Not Considered in the evaluation of the deformation capacity increase. 
The load versus central deflection responses (recorded by LVDT 1) in the tested prototypes are presented in Fig.8, where a remarkable improvement on the out-of-plane prototype behaviour provided by the strengthening system is visible. Furthermore, the behaviour of FRM_1 and FRM_2 was quite similar up to peak load, proving that the proposed strengthening technique, based on the use of very ductile materials, is very efficient in terms of reducing the intrinsic heterogeneity of this quite brittle masonry schist constructions. From the area behind these curves, it was evaluated the energy absorption capacity of these prototypes up to the central deflection corresponding to the peak load, and the values of 3.95 N.mm and 93.64 N.mm were obtained for the reference and strengthened prototypes, respectively. This increase, of $2371 \%$, demonstrates the effectiveness of the proposed strengthening technique in terms of energy absorption enhancement for this type of construction systems.

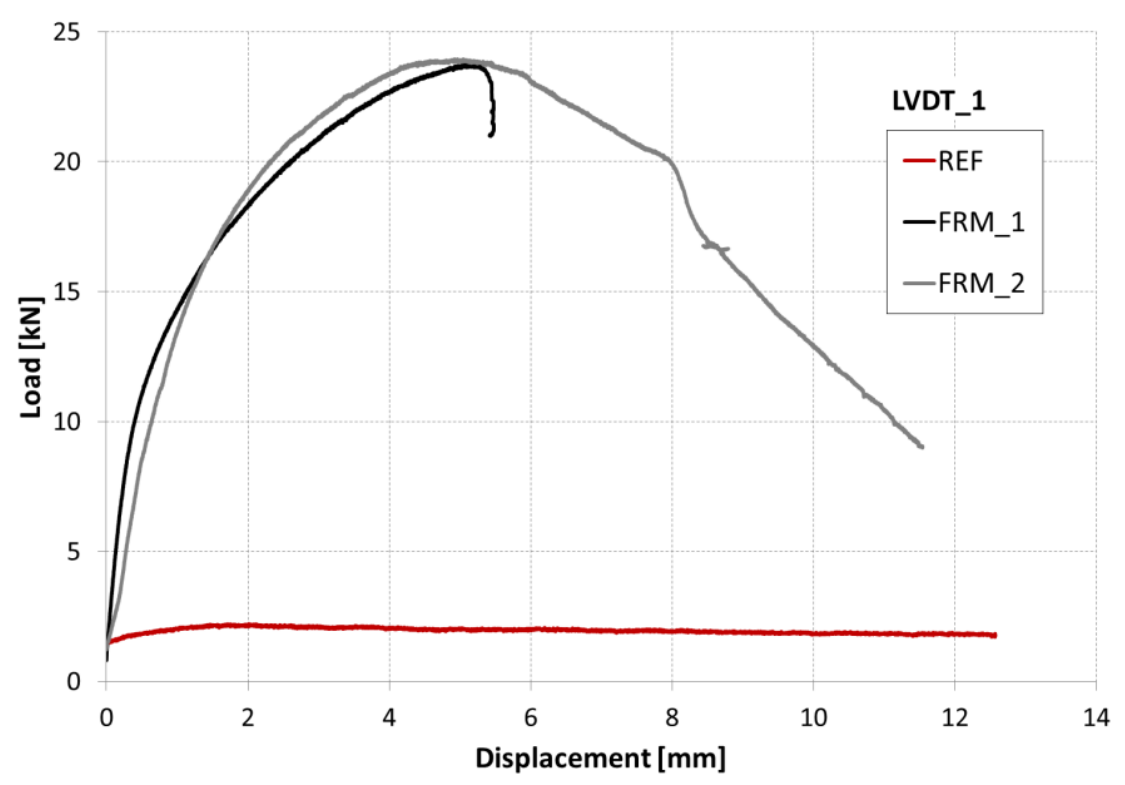

Fig. 8 - Comparison of load vs central deflection (LVDT_1)

\section{$4 \quad$ Numerical modelling}

In order to deeper investigate the potentialities of the proposed technique for the strengthening of schist masonry type constructions, a finite element analysis was carried out, by using a computer code with constitutive models capable of simulating the relevant nonlinear phenomena involved. For this purpose, FEMIX 4.0 [31] computer program was adopted, whose predictive performance was first assessed by simulating the tested schist masonry prototypes. FEMIX 4.0 is a software whose purpose is the analysis of structures by the Finite Element Method (FEM). This program is based on the displacement method, possessing a large library of types of finite elements available, namely 3D frames and trusses, plane stress elements, flat or curved elements for shells, and 3D solid elements. 
Linear elements may have two or three nodes, plane stress and shell elements may be 4, 8 or 9-noded and 8 or 20 -noded hexahedra may be used in 3D solid analyses. This element library is complemented with a set of point, line and surface springs that model elastic contact with the supports, and also several types of interface elements to model inter-element contact. Embedded line elements can be added to other types of elements to model reinforcement bars. All these types of elements can be simultaneously included in the same analysis, with the exception of some incompatible combinations. The analysis may be static or dynamic and the material behaviour may be linear or nonlinear. Data input is facilitated by the possibility of importing CAD models. Post processing is performed with a general purpose scientific visualization program named Drawmesh, or more recently by using GID. At this stage of the study, the main purpose was to derive information for the definition of the parameters of the constitutive models used to simulate the behaviour of the applied materials, namely schist masonry and FRM. This derivation process was executed by performing inverse analysis by fitting, as best as possible, the results of the experimental tests with the schist prototypes. A macromodelling approach was adopted for the discretization of the schist masonry part of the prototype, since its dimensions and the irregular and unpredictable arrangement of the units do not allow to follow a micro-modelling approach.

The 2D multi-directional fixed smeared crack model described in [32], available in the FEMIX computer program, was used in the numerical simulations. To simulate the crack initiation and the fracture mode I propagation of the constituent materials of the schist masonry prototypes, the quadrilinear tension-softening diagram represented in Fig. 9a was adopted [33], which is defined by the parameters $\alpha_{i}$ and $\xi_{i}$, relating stress with strain at the transitions between the linear segments that compose this diagram. The ultimate crack strain, $\varepsilon_{n, u}^{c r}$, is defined as a function of the parameters $\alpha_{i}$ and $\xi_{i}$, the mode I fracture energy, $G_{f}^{I}$, the tensile strength, $\sigma_{n, 1}^{c r}=f_{c t}$, and the crack bandwidth, $l_{b}$ [33]. This last parameter assures that the results are not dependent of the refinement of the finite element mesh.

In the present simulations the arc-length technique was used in order to simulate the real tests conditions, where load was applied in displacement control, at the displacement rate of $0.01 \mathrm{~mm} / \mathrm{s}$.

\subsection{Finite element mesh and boundary conditions}

The numerical simulations were performed using a simplified macro-modelling approach where the heterogeneous system composed of schist units bonded by HLM mortar joints was considered as a continuum medium. Thus, 8-noded quadrilateral plane stress elements with 2 x 2 Gauss-Legendre integration scheme was adopted for simulating both the schist-HLM and FRM. Finite elements of $50 \times 50 \mathrm{~mm}^{2}$ dimensions were adopted for the schist-HLM medium, while finite elements of 25x50 $\mathrm{mm}^{2}$ were considered for the two outer layers of FRM. 
To simulate the support conditions of the tested prototypes, a null value was assumed for the vertical displacement (Y direction) of the nodes of the finite element mesh coinciding with the bottom edge of the prototype (that is in contact with the supporting plate), as well as for horizontal displacement (X direction) of the nodes that are in contact with the lateral I steel profiles (one node for each support) of the steel reaction frame.

\subsection{Simulation of the experimental test with the unstrengthened prototype}

To apply the adopted multi-directional fixed smeared crack model, the data defining the complete tensile behaviour of the materials should be provided, namely, the elasticity modulus and the tensile strength, and the diagram that simulates the fracture mode I propagation. For this purpose, the quadrilinear tensile-softening diagram represented in Fig. 9a was used, since by changing the normalized coordinates $\left(\xi_{i}, \alpha_{i}\right)$ that define the transition points of this diagram, materials with tensionsoftening or tension-stiffening character can be simulated [34].

According to the authors knowledge, no research has been carried out with the purpose of evaluating the tensile-softening law of schist masonry, therefore no experimental data is available in this respect. Some ranges of $\left(\xi_{i}, \alpha_{i}\right)$ values were assumed taking into account the brittle nature of this construction system, as well as for the tensile strength $\left(f_{c t}\right)$ and mode I fracture energy $\left(G_{f}\right)$ of the schist masonry. Table 2 includes the ranges of values adopted for these parameters, while Fig. 9b represents the corresponding envelope and average quadrilinear diagrams.

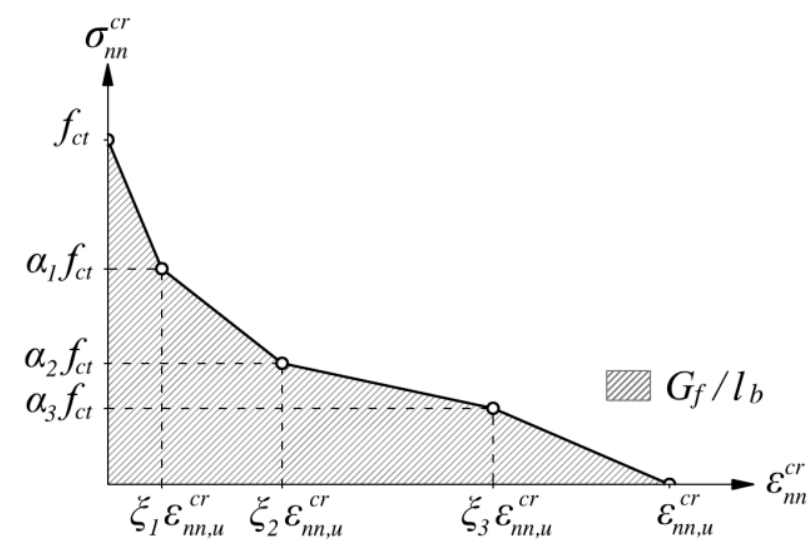

(a)

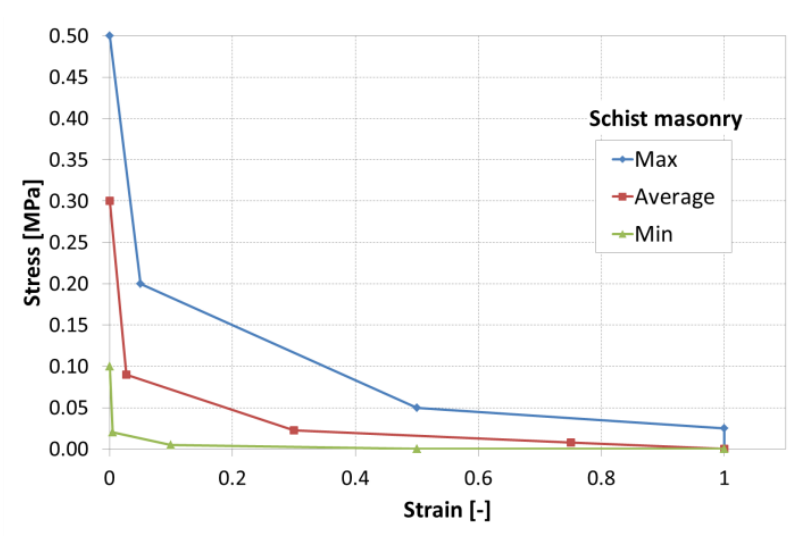

(b)

Fig. 9 - a) Quadrilinear diagram for modelling the fracture mode I component of crack constitutive law of the multi-directional smeared crack model [34]; b) Diagrams adopted for simulating the schist masonry. 
Table 2 - Schist masonry parameters range.

\begin{tabular}{ccc}
\hline Tensile strength & $f_{c t}[\mathrm{MPa}]$ & {$[0.1 \div 0.5]$} \\
Fracture energy & $G_{f}[\mathrm{~N} / \mathrm{mm}]$ & {$[0.05 \div 0.1]$} \\
\hline \multirow{2}{*}{ 1st post peak } & $\xi_{1}[-]$ & {$[0.005 \div 0.05]$} \\
& $\alpha_{1}[-]$ & {$[0.2 \div 0.4]$} \\
\hline \multirow{2}{*}{ 2nd post peak } & $\xi_{2}[-]$ & {$[0.1 \div 0.5]$} \\
& $\alpha_{2}[-]$ & {$[0.05 \div 0.1]$} \\
\hline \multirow{2}{*}{ 3rd post peak } & $\xi_{3}[-]$ & {$[0.5 \div 1.0]$} \\
& $\alpha_{3}[-]$ & {$[0.0 \div 0.05]$} \\
\hline
\end{tabular}

In an attempt of simulating the sudden failure in the interface between schist units and mortar joints observed in the experimental program, an abrupt decay on the tensile-softening diagram just after crack initiation was assumed (see Fig. 9b). Moreover, for modelling the very weak and fragile behaviour of this construction system, relatively low values for the tensile strength and fracture energy were considered.

The numerical simulations pointed out that both the tensile strength $\left(f_{c t}\right)$ and the $1^{\text {st }}$ post-peak point coordinates $\left(\xi_{1}, \alpha_{1}\right)$ influence the pre-peak trend of the load-deflection response of this prototype (the peak load and its deflection increase with the increase of the values of these parameters), whereas the fracture energy $\left(G_{f}\right)$ conditioned mostly the post-peak branch by assuring higher post-peak resisting load with the increase of $G_{f}$. Additionally, the accurate capture of the first crack appearance was quite dependent on the values attributed to $f_{c t}$ and $\left(\xi_{1}, \alpha_{1}\right)$ parameters.

Considering the force versus the displacement registered in the LVDT 1 (central deflection of the prototype), an inverse analysis procedure was executed in order to determine the fracture parameters of the material composite system that best fits the experimental response. Fig. 10 shows the numerical response that has best fitted the experimental one, and the corresponding values of the model's parameters are indicated in Table 3. 


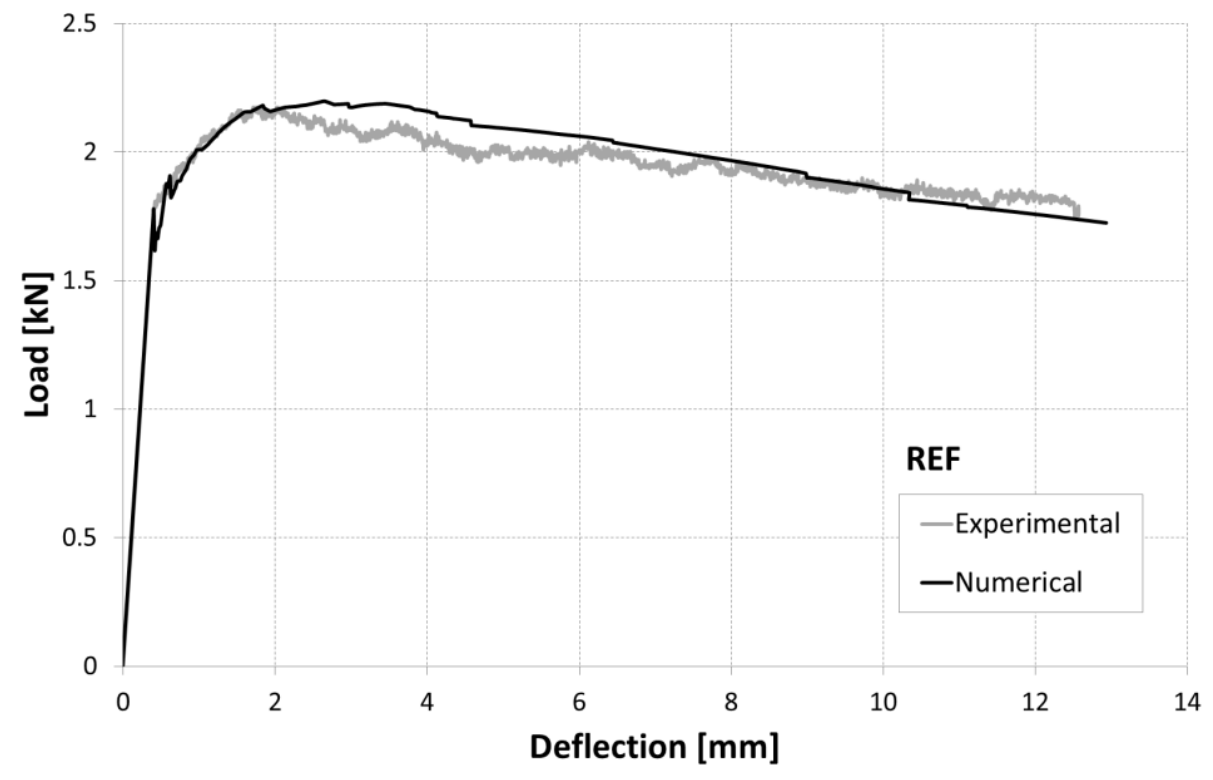

Fig. 10 - Experimental and numerical load vs central deflection response of REF prototype.

Table 3 - Adopted parameters of the constitutive model of the schist masonry.

\begin{tabular}{ccccccccc}
\hline $\begin{array}{c}E \\
{[\mathrm{MPa}]}\end{array}$ & $\begin{array}{c}f_{c t} \\
{[\mathrm{MPa}]}\end{array}$ & $\begin{array}{c}\xi_{1} \\
{[-]}\end{array}$ & $\alpha_{1}$ & $\xi_{2}$ & $\alpha_{2}$ & $\xi_{3}$ & $\alpha_{3}$ & $G_{f}$ \\
{$[-]$} & {$[-]$} & {$[-]$} & {$[-]$} & {$[-]$} & {$[\mathrm{N} / \mathrm{mm}]$} \\
\hline 500 & 0.1 & 0.003 & 0.33 & 0.6 & 0.1 & 0.85 & 0.035 & 0.15 \\
\hline
\end{tabular}

Finally, the crack patterns analysed at the peak load and at ultimate deflection were compared to the experimental ones and reported in Fig. 11. As can be observed, some inconsistencies between experimental and numerical crack patterns occurred at the peak load. The numerical simulation revealed the existence of cracks at the lower part of the model for the peak load, while in tested prototype it occurred shortly after the peak load. This divergence was used by simplifications adopted to simulate the bottom support conditions that restrain the vertical displacements of the corresponding nodes, favouring a premature formation of this crack. However, due to the localization of this crack and considering the relatively low tensile strength of this composite material, the numerical model capture accurately the overall behaviour of the unstrengthened prototype, showing a main fracture in the mid-span, which has mainly driven the failure mechanism (see Fig. 11d). 


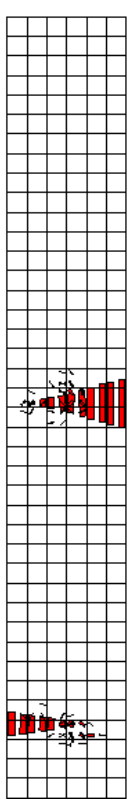

(a)

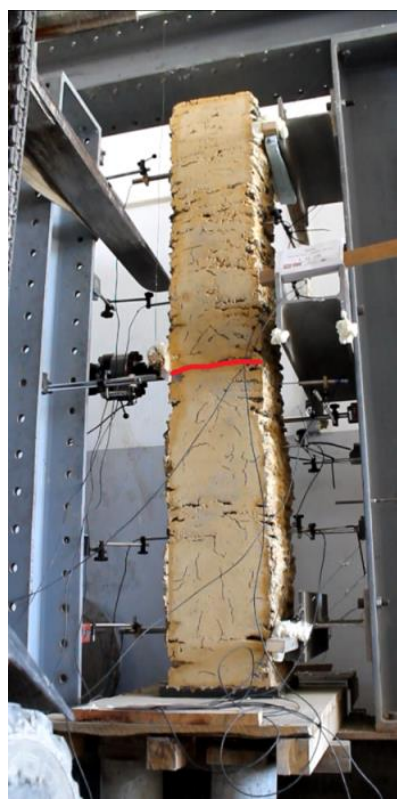

(b)

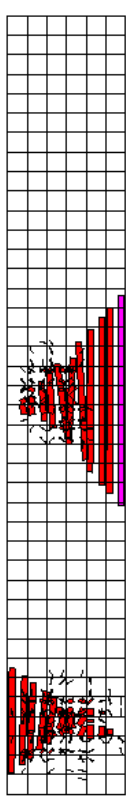

(c)

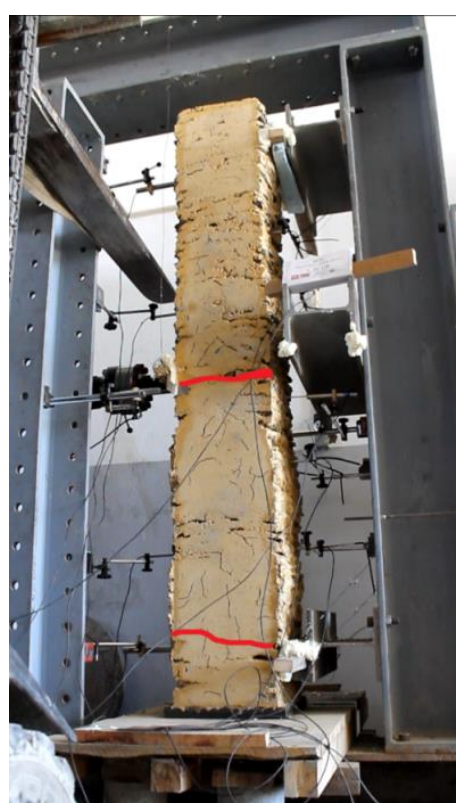

(d)

Fig. 11- Crack pattern of REF prototype at: peak load (a) numerical (only cracks at opening stage are represented), (b) experimental; end of the test: (c) numerical (only cracks at opening and completely open stages are represented), (d) experimental.

\subsection{Simulation of the experimental tests with the strengthened prototypes}

Once the parameters of the constitutive model of the schist masonry were derived (see Table 3 ), the values of the constitutive model for simulating the tensile behaviour of FRM were determined by also using an inverse approach similar to the one adopted for the schist-mortar material system. In fact, the quadrilinear diagram represented in Fig. 12 was adopted to simulate the post cracking behaviour of the FRM material, and the parameters for its full characterization, namely, $\left(\xi_{i}, \alpha_{i}\right), f_{c t}$ and $G_{f}$ were obtained by performing an inverse analysis by fitting, as best as possible, the force versus central deflection response of the experimentally tested FRM_2 prototype (see Fig. 13) .

The diagram represented in Fig. 12 shows that the post-cracking tensile behaviour of FRM is characterized by an abrupt tensile stress decay just after crack initiation, followed by a pseudohardening branch up to almost $40 \%$ of the ultimate tensile strain, and then an almost linear descending branch governs this stage of the crack opening process. By considering the crack band width adopted in the numerical simulations (equal to the square root of the area of the integration point) and the area behind the quadrilinear stress-strain diagram of Fig. 12, a mode I fracture energy of $7.0 \mathrm{~N} / \mathrm{mm}$ was obtained for the FRM applied in the strengthened prototype. The values that fully define the diagram of Fig. 12 are indicated in Table 4. 


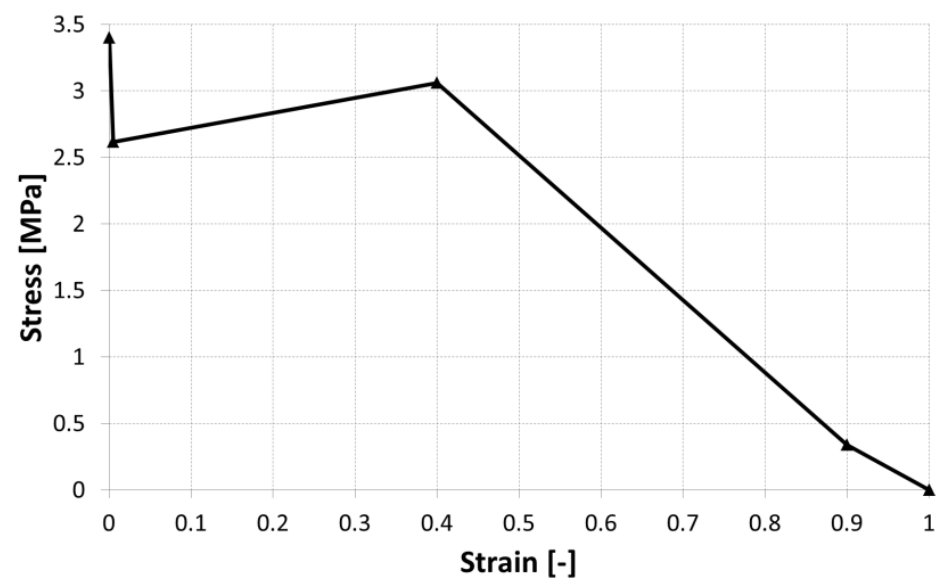

Fig. 12 - Diagram that characterizes the fracture mode I propagation of the FRM applied in the strengthened prototypes.

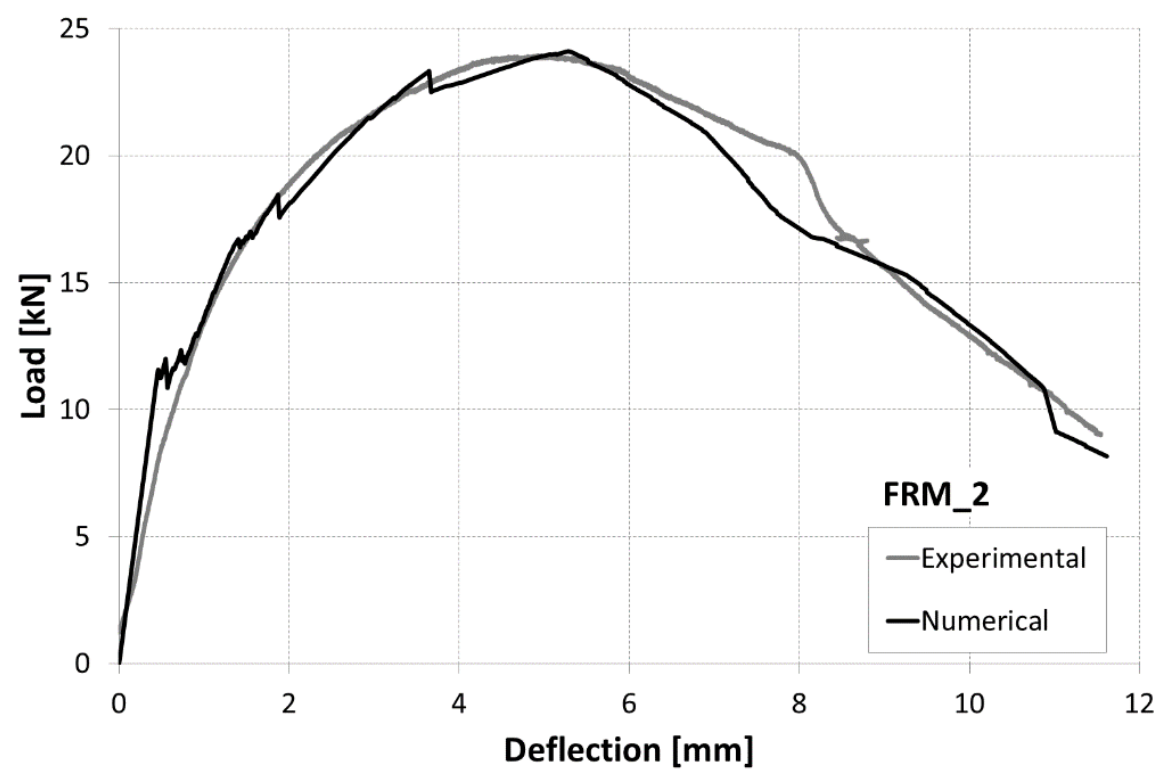

Fig. 13 - Experimental and numerical force versus central deflection of the FRM_2 prototype.

Table 4 - Values of the properties that define the tensile behaviour of FRM applied in the strengthened prototypes.

\begin{tabular}{ccccccccc}
\hline$E$ & $f_{c t}$ & $\xi_{1}$ & $\alpha_{1}$ & $\xi_{2}$ & $\alpha_{2}$ & $\xi_{3}$ & $\alpha_{3}$ & $G_{f}$ \\
{$[\mathrm{GPa}]$} & {$[\mathrm{MPa}]$} & {$[-]$} & {$[-]$} & {$[-]$} & {$[-]$} & {$[-]$} & {$[-]$} & {$[\mathrm{N} / \mathrm{mm}]$} \\
\hline 11 & 3.4 & 0.005 & 0.77 & 0.4 & 0.9 & 0.9 & 0.1 & 7.0 \\
\hline
\end{tabular}

Finally, the crack patterns at the peak load and at ultimate deflection obtained numerically are compared to the experimental ones in Fig. 14. In this case, the numerical model results did not reflect correctly the experimental ones. Due to the reasons already pointed out for the crack pattern in the reference prototype, the numerical and experimental crack patterns in the top half part of the strengthened prototypes present some deviations (see Fig. 14). Nevertheless, the numerical model 
was able to capture accurately the global response of the prototype, the formation of the shear cracks observed in the core schist part of the prototype, and some micro-cracks in the FRM layer in tension.

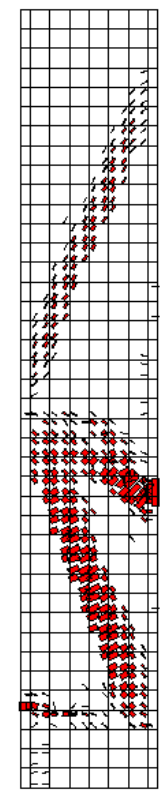

(a)

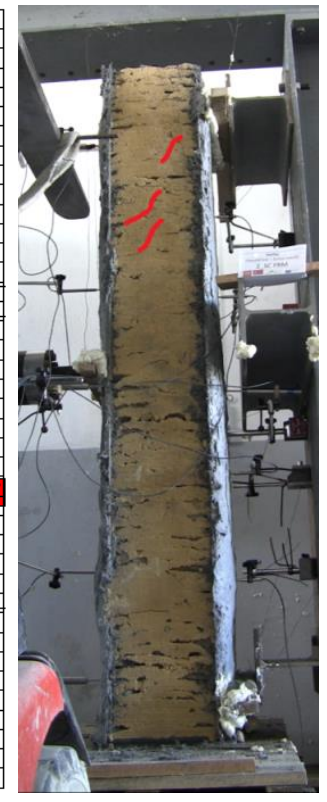

(b)

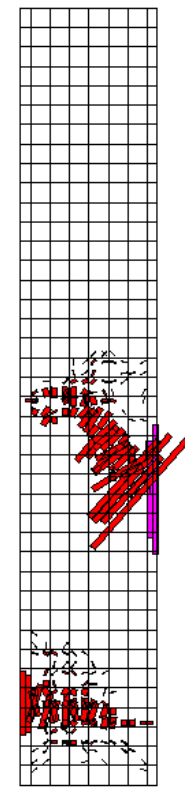

(c)

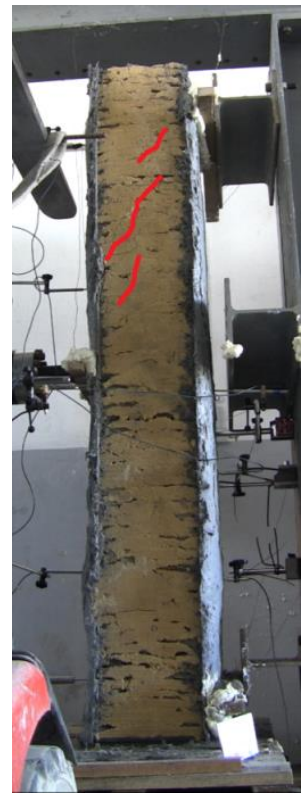

(d)

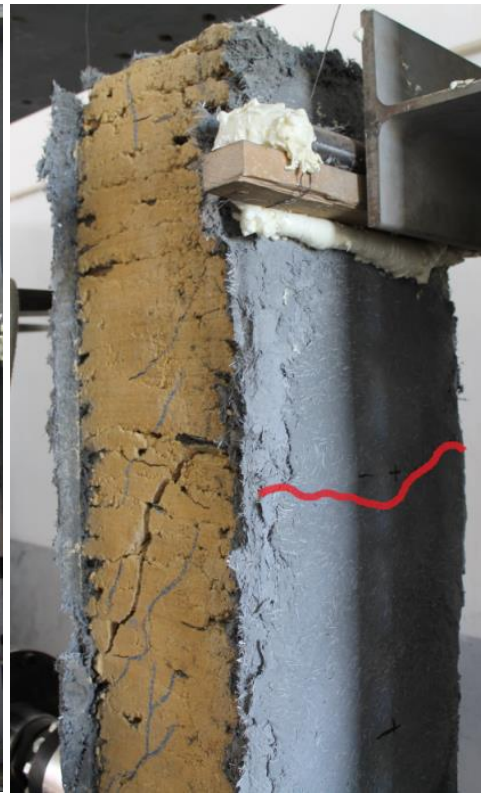

(e)

Fig. 14 - Crack pattern at: peak load (a) numerical (only cracks at opening stage are represented), (b) experimental; the end of the test: (c) numerical (only cracks at opening and completely open stages are represented), (d\&e) experimental.

\section{$5 \quad$ Parametric analysis}

To explore the potentialities of the proposed FRM-based strengthening technique, a parametric analysis was performed. In particular, it was investigated how the thickness $(t)$, the fracture energy $\left(G_{f}\right)$ and the post-cracking behaviour of the FRM affected the load-deflection responses of the strengthened prototypes. Thus, two sets of values for the FRM layer thickness were considered (15 $\mathrm{mm}$ and $35 \mathrm{~mm})$ and for each one, three sets of values for the FRM fracture energy $\left(\mathrm{G}_{\mathrm{f} 2}=2 \mathrm{~N} / \mathrm{mm}\right.$; $\mathrm{G}_{\mathrm{f} 5}=5 \mathrm{~N} / \mathrm{mm} ; \mathrm{G}_{\mathrm{f} 8}=8 \mathrm{~N} / \mathrm{mm}$ ) were analysed. Moreover, each simulation was executed assuming three different shapes (S1, S2, S3) of the FRM quadrilinear tensile-softening diagram (see Fig. 15). 


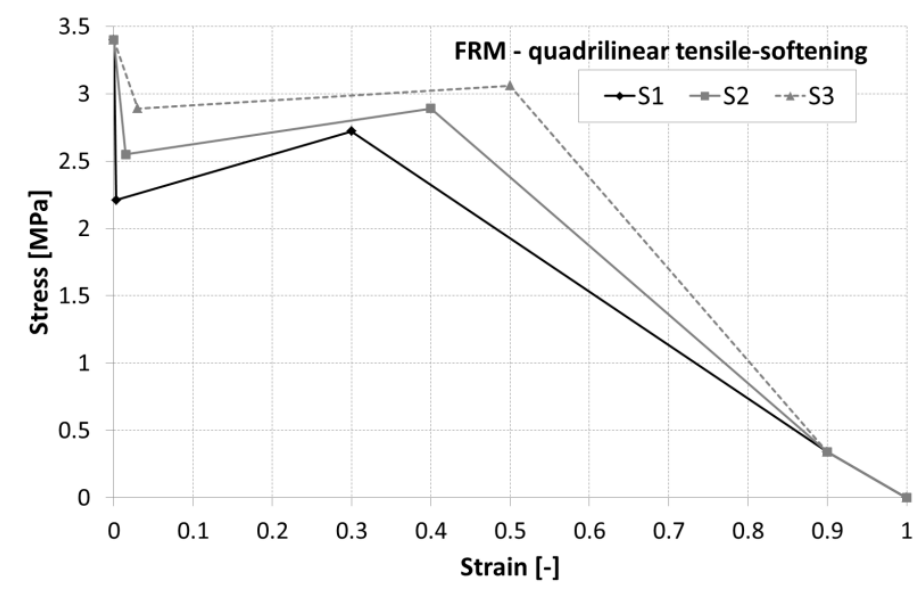

Fig. 15 - FRM quadrilinear tensile softening diagrams adopted.

Fig. 16 summarizes the results of the numerical simulations for FRM layers $15 \mathrm{~mm}$ thick (T15) and $35 \mathrm{~mm}$ thick (T35). In the legends of this figure, TxGfy represents the simulation where a FRP layer of $\mathrm{x}(\mathrm{mm})$ thickness and $\mathrm{y}(\mathrm{N} / \mathrm{mm})$ mode I fracture energy was used. Each graph of this figure includes three curves, each one corresponding to a $\mathrm{Si}(\mathrm{i}=1,2,3)$ diagram in terms of crack normal stress versus crack normal strain.

The results show that for the shapes considered for the tensile-softening diagram (assumed representative of the FRM that can be developed for the proposed strengthening technique), the load carrying capacity of the prototype increases with the post cracking tensile strength of the second branch of the FRM softening diagram (see Fig. 15). However, when this happen the third branch of this diagram simulates a higher tensile stress decay with the strain normal to the crack, whose consequence on the response of the prototype is a more abrupt load decay after peak load (more brittle response). These trends are as pronounced as larger is the FRM layer thickness and its mode I fracture energy. The shapes adopted for this diagram do not have influence on the load at crack initiation, and have also minor influence on the response of the prototype up to the peak load when the fracture energy and/or the thickness of the FRM layer are relatively small.

By increasing the FRM layer thickness from $15 \mathrm{~mm}$ to $35 \mathrm{~mm}$, the peak load $\left(F_{\text {peak }}\right)$ of the prototype has increased $[105 \div 109] \%,[114 \div 123] \%$ and $[120 \div 126] \%$ when $G_{f}=2,5$ and $8 \mathrm{~N} / \mathrm{mm}$ were adopted, respectively (the minimum and maximum values of the intervals correspond to $\mathrm{S} 1$ and $\mathrm{S} 3$, respectively). In terms of deflection at peak load $\left(\mathrm{U}_{\text {peak }}\right)$, this increase was $[21 \div 49] \%,[-1 \div 31] \%$ and $[-1 \div 2] \%$, respectively. Therefore, the peak load of the prototype is mainly governed by the thickness of the FRM layer, while the deflection performance (ductility) is mainly controlled by the mode I fracture energy of this material. In any case, as pronounced is the pseudo-hardening character of the FRM material (defined by the second branch of the post-cracking diagram) as larger is the peak load and its deflection, but with minor impact than the thickness and the fracture energy of the FRM material in terms of that respective performance indicators of the prototype response. 

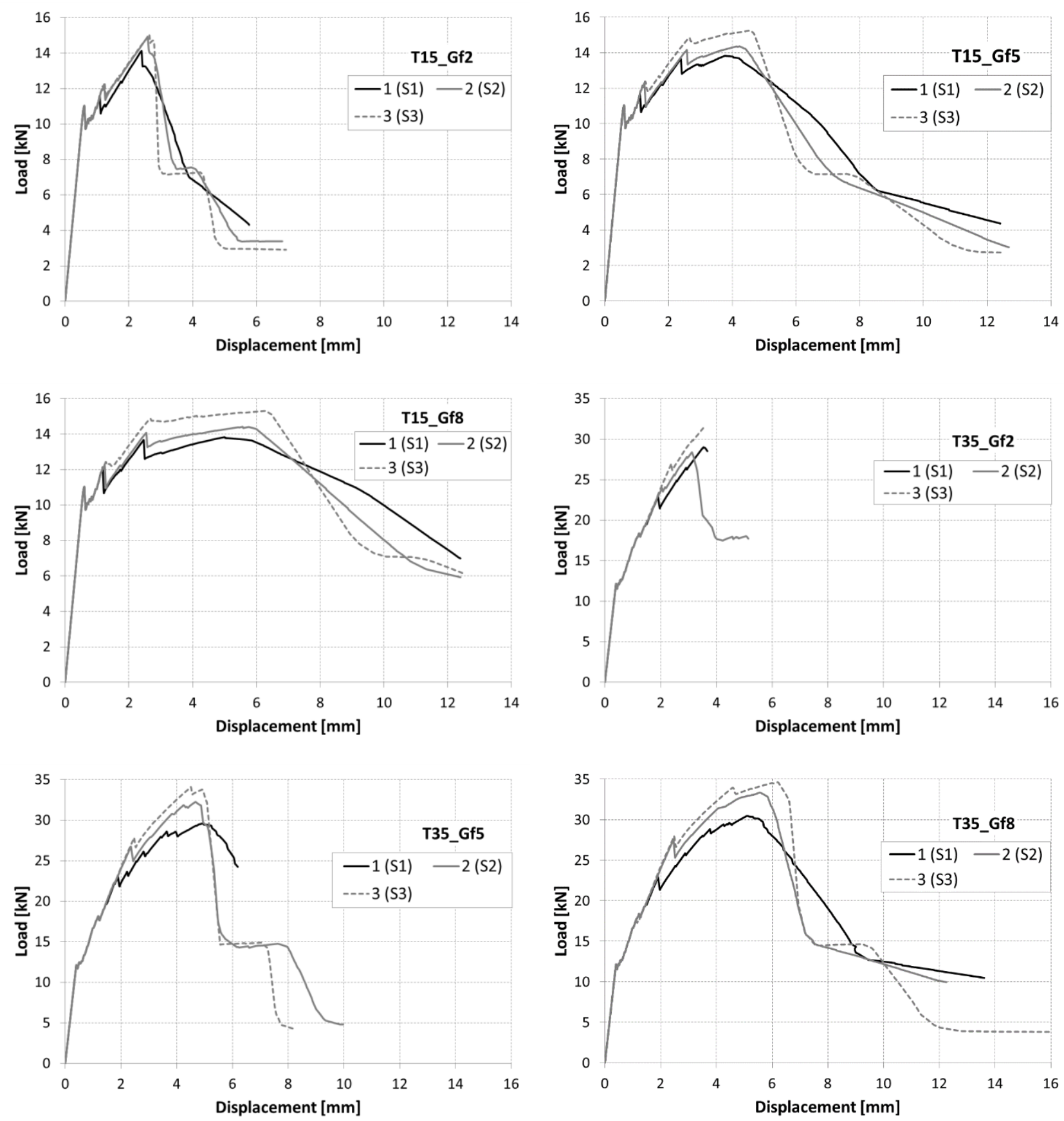

Fig. 16 - Load vs mid-span displacement relationship.

A more comprehensive representation of the influence of $t$ and $G_{f}$ on the relevant behaviour of the strengthened prototypes is provided in Fig. 17. In particular, Fig. 17 shows how the thickness significantly affects the $F_{\text {peak }}$, while the fracture energy plays minor role in this respect. On the contrary, $G_{f}$ has a high influence on the deformation at the peak load $\left(U_{\text {peak }}\right)$, at $75 \%$ of the peak load $\left(\mathrm{U}_{75}\right)$ and to the $50 \%$ of the peak load $\left(\mathrm{U}_{50}\right)$. 


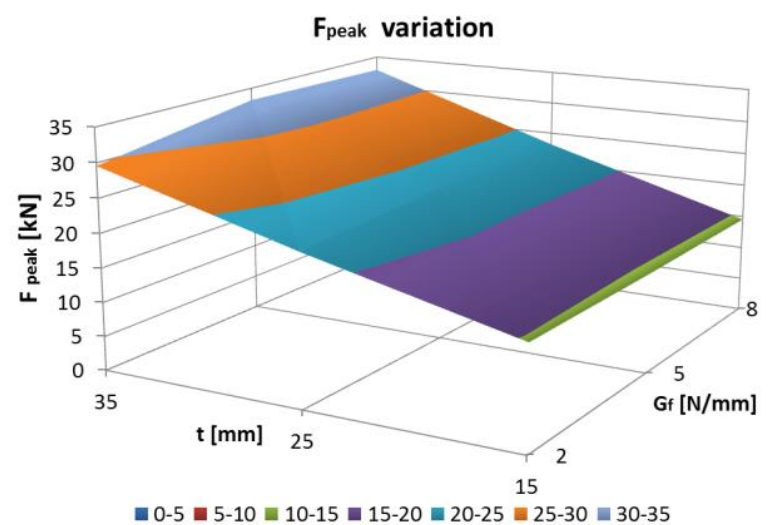

(a)

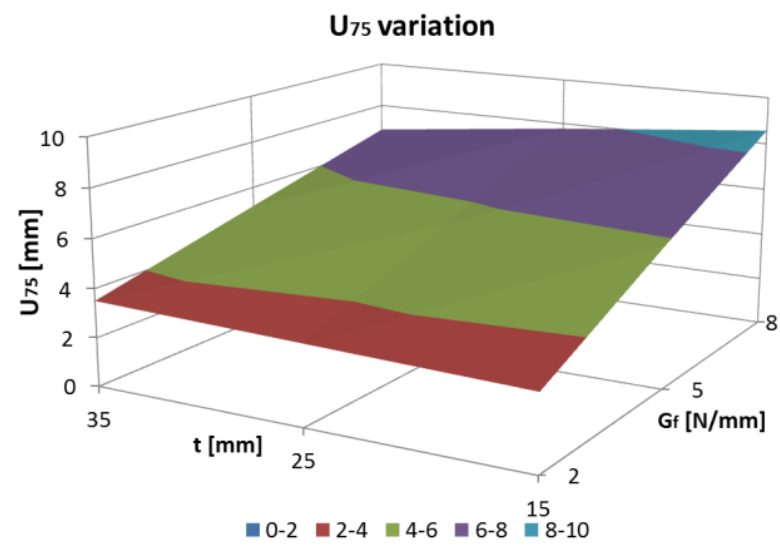

(c)

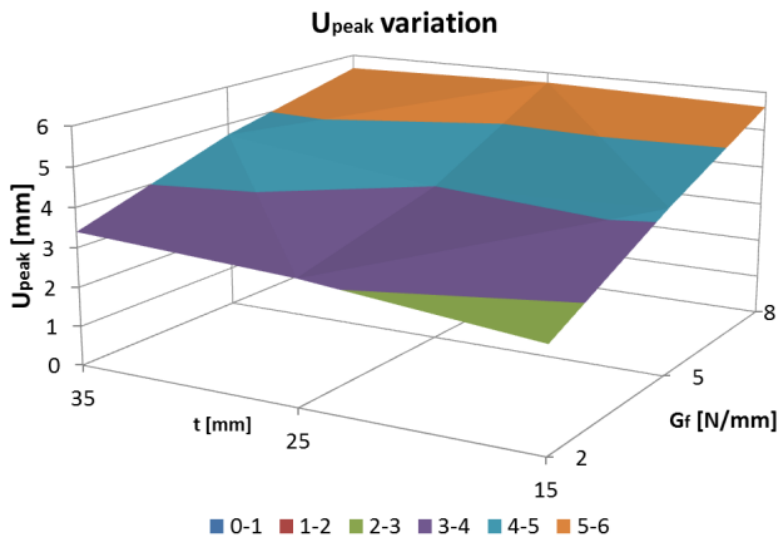

(b)

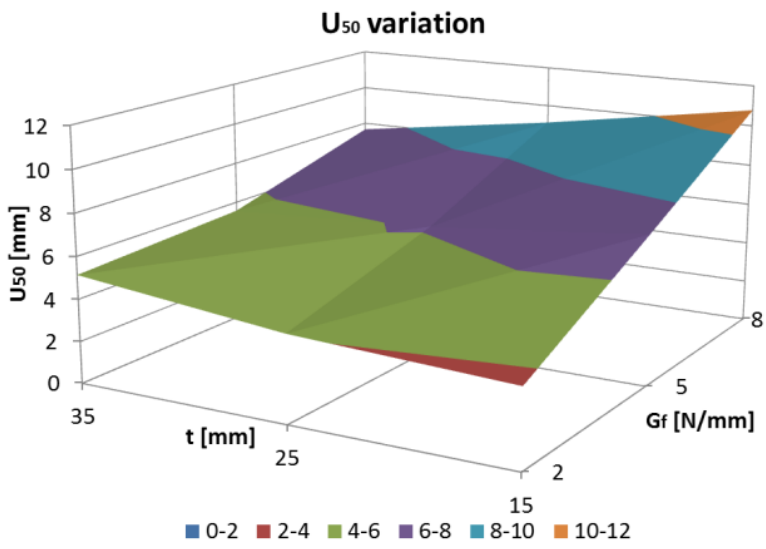

(d)

Fig. 17 - Influence of $t$ and Gf on: (a) Peak load; (b) Peak displacement; (c) Displacement correspondent to 75\% of the peak load; (d) Displacement correspondent to $50 \%$ of the peak load.

The parametric analysis on the influence of the strengthening system properties on the prototype response has revealed that:

a) the load carrying capacity is mainly influenced by the applied FRM thickness, and it is slightly governed by the FRM second branch of the tensile-softening model;

b) the ductility is governed by the fracture energy and the slope of the FRM third branch quadrilinear tensile-softening diagram. In particular, the influence of $G_{f}$ is more relevant for smaller FRM layer thicknesses (see Fig. 17d).

\section{Conclusions}

This work studies the application of an innovative reinforcement system, based on spraying thin layers of FRM to strengthen schist masonry walls subjected to out-of-plane load conditions.

The use of the spraying technology for the application of the FRM was analysed by comparing the mechanical performance of samples extracted from panels that were manufactured with the spraying technique (vertical casting) and with horizontal pouring of the FRM. The FRM samples extracted 
from the horizontally casted panel showed a more ductile response than samples obtained by the spraying procedure. This difference is based on the presence of more voids in the latter type of samples. It was also identified that the FRM exhibits an anisotropic behaviour that is related with the preferential direction applied with a roller during casting. The flexural strength of the FRM is higher for the samples co-axial with the rolling direction.

The application of two layers of FRM, with $25 \mathrm{~mm}$ of thickness, to strengthen schist masonry walls submitted to 3-point bending test resulted in an extraordinary increase of the load carrying and deformation capacity of the specimens, specifically the peak load and the displacement at peak load were 10x and 4.8x higher than the observed values in the unreinforced specimen, respectively. Additionally, the dissipated energy exhibited by the reinforced samples revealed an exceptional increase of ductility when compared with the reference specimen.

A FEM model was implemented in order to numerically simulate the experimental program. The constitutive models of the FRM and the schist masonry elements were derived from the experimental data. The numerical models were able to capture the global response of the tested prototypes; however, some discrepancies between the crack patterns arise, pointing to the need to carry further research in this topic.

A parametric analysis was carried in order to identify the influence of the properties of the FRM on the performance of the strengthening system, namely the strengthening layer thickness. It was observed that the load carrying capacity is mainly influenced by the FRM layer thickness; and that the ductility of the strengthening system is governed by the fracture energy and the tensile softening diagram shape adopted for the FRM.

\section{Acknowledgments}

The author wish to acknowledge CiviTest, Lda (Jesufrei, Portugal) for supporting the experimental program, the sustain provided by INOTEC - Innovative material of ultra-high ductility for the rehabilitation of the built patrimony, QREN project number 23024, and the collaboration of the companies Owens Corning, Exporplas, Sika, Chryso and SECIL for providing, respectively, glass fibres, polypropylene fibres, superplasticizers, Viscous Modifier Agent, and Cement.

The authors further wish to acknowledge the Erasmus Plus and Placement Mobility Programs among the University of Ferrara (Italy), the University of Minho (Portugal) and the CiviTest Lda (Portugal) which made this international cooperation possible. 


\section{References}

[1] Boeri A., «Pietre Naturali nelle Costruzion», Milan, Hoepli, 1996, pp. 12-52.

[2] Barroso, C.E. et al., "The vernacular house between the Cavado and the Ave, Portugal", Vernacular Heritage and Earthen Architecture: Contributions for Sustainable Development, pp. 351357,2014

[3] Moutinho M., The popular Portuguese architecture (in Portuguese), Lisbon: Editorial Estampa, 1995.

[4] Barros R.S., Oliveira D.V., Varum H., "Typological characterization of the Portuguese traditional schist constructions", in XXXVII IAHS, Santander, 2010.

[5] Como M., "Statics of Historic Masonry Constructions”, Roma, Springer, 2013, pp. 509-585.

[6] Bell F.G., "Engineering geology", ELSEVIER, Oxford, 2007.

[7] Oliveira D.V., Experimental and numerical analysis of blocky masonry structures under cyclic loading, Universidade do Minho, Guimarães Portugal: PhD Thesis, 2003.

[8] Bothara J., Brzev S., "A Tutorial: Improving the Seismic Performance of Stone Masonry Buildings", Earthquake Engng. Res. Inst., vol. 94612, n 1934, pp. 53-71, 2011.

[9] El Gawady M., Lestuzzi P., Badoux M., "A Review of Conventional Seismic Retrofitting Techniques for URM.1-9.", in 13th Internat., Brick a. Block Masonry Conf., Amsterdam, July 4-7, 9, 2004.

[10] Candeias P., Costa A. C., Coelho E., "Seismic Strengthening of Old Masonry Buildings with Application of GFRP's", in 1st US-Portugal Internat. Workshop on Grand Challenges in Earthquake Engng. $25^{\circ}$ Years after the 1755 Lisbon Earthquake, Lamego, Portugal, 2005.

[11] Borri A., Corradi M., Vignoli A., Seismic Upgrading of Masonry Structures with FRP., 2003.

[12] Bosiljkov V., "Micro vs Macro Reinforcement of Brickwork Masonry," Mater. A. Struct, vol. 39, pp. 235-245., 2006.

[13] S. R.A., "Seismic Strengthening of Masonry in Buildings and Cultural Heritage", Proc. Of the 6th National Congress on Seismol. A. Seismic Engng. SISMICA, vol. 1, pp. 81-100, 2004.

[14] B. Ghiassi, Durability analysis of bond between composite materials and masonry substrates, University of Minho: PhD Thesis, 2013.

[15] Drysdale R. G., Hamid A. A., Baker L. R., Masonry structures: behavior and design., Boulder, Colorado, USA: The Masonry Society, 1999. 
[16] Lourenço P.B., "A review of out of out-of-plane behavior of masonry", Masonry International, vol. $14, \mathrm{n}^{\circ} 3$, pp. 67-73, 2001.

[17] Liu Y., Dawe J., Moxon D., "Reinforced masonry concrete block walls under combined axial and uniformly distributed lateral load., paper $n^{\circ} 216$.", in Proceedings of 13th International Brick and Block Masonry Conference, Amsterdam, Netherlands, 2004.

[18] Costa A., Arede A., Costa A. \& Oliveira C.S., "In situ cyclic tests on existing stone masonry walls and strengthening solutions", Earthquake Engineering and Structural Dynamics, n 40, pp. 449$471,2011$.

[19] Dizhur D., Derekhshan H., Lumantarna R. \& Ingham J., "Earthquake-Damage unreinforced masonry building tested in situ", Journal of the Structural Engineering, vol. 23, n² 2, pp. 76-89, 2010.

[20] Barros R.S., Oliveira D.V., Varum H., Alves C. a. S., and Camões A., "Experimental characterization of physical and mechanical properties of schist from Portugal", Construction and Building Materials Journal, vol. 50, pp. 617-630, 2014.

[21] CEN BS EN 459-1, Building lime - Definitions, specifications and conformity criteria, 2002.

[22] CEN EN 1015-3, Methods of test for mortar for masonry. Part 3: Determination of dry bulk density of hardened mortar, 1999.

[23] Valente, T.D.S., Gonçalves, D.M.F., Frazão, C.M.V., Barros, J.A.O., "High ductility mortar for rehabilitation: mechanical properties and durability", 5th Portuguese Conference of Structural Engineering, JPEE, LNEC, November 2014 (in Portuguese).

[24] CEN EN 1015-7, Methods of test for mortar for masonry. Part 7: Determination of air content of fresh mortar, 1998.

[25] CEN - BS EN 1015-11, Methods of test for mortar for masonry - Part 11: Determination of flexural and compressive strength of hardened mortar, 2007.

[26] CEN - BS EN 1015-12, Methods of test for mortar for masonry - Part 12: Determination of adhesive strength of hardened rendering and plastering mortars on substrates, 2000.

[27] Almeida J.A.P.P., Bordigoni D., Pereira E.N.B., Barros J.A.O., Aprile A., "Assesment of the properties to characterize the interface between clay brick substrate and strengthening mortar", Construction and Building Materials Journal, 2015.

[28] ASTM standard C1609/C1609M-12, "Standard Test Method for Flexural Performance of Fiber-Reinforced Concrete (Using Beam With Third-Point Loading)", n 2013, pp. 1-9. 
[29] Pereira, E.N.B., Fischer, G., Barros, J.A.O., "Effect of hybrid fiber reinforcement on the cracking process in fiber reinforced cementitious composites", Cement and Concrete Composites Journal, 34, 1114-1123, 2012.

[30] Colombo M., Strengthening of schist walls elements: experimental and numerical research, Master Thesis, 2014.

[31] Azevedo A.F.M., Barros J.A.O., and Sena Cruz J.M., "Educational software for the design of structures”, Proceedings of III Congresso de Luso_Moçambicano de Engenharia Mozambique, pp. 81-92, 2003.

[32] Sena-Cruz, J.M., Barros, J.A.O., Azevedo, A.F.M. and Ventura-Gouveia, A., "Numerical simulation of the nonlinear behavior of RC beams strengthened with NSM CFRP strips", in Proceedings of CMNE/CILAMCE Congress, FEUP, Porto, Portugal, 2007.

[33] A. Ventura-Gouveia, "Constitutive models for the material nonlinear analysis of concrete structures including time-dependent effects", University of Minho, Guimaraes, Portugal, PhD Thesis, 2011.

[34] Salehian, H; Barros, J.A.O., "Assessment of the performance of steel fibre reinforced selfcompacting concrete in elevated slabs", Cement and Concrete Composites, $\mathrm{n}^{\circ}$ 55, pp. 268-280, January 2015. 